\title{
Introduction to the special issue "What is really information? An interdisciplinary approach"
}

\author{
J osé María Díaz Nafría, Francisco Salto Alemany² \\ Universidad de León, Facultad de Filosofía y Letras, 24071 León, Spain \\ Email: ${ }^{1}$ jnafria@uax.es, ${ }^{2}$ francisco.salto@unileon.es
}

\begin{abstract}
Acknowledgement: The editors of these special issue wish to express their gratitude to TripleC for the occasion of bringing to the international scientific community the works presented at the I International Meeting of Experts in Information Theories - An interdisciplinary approach held in León (Spain) in November 2008. In a first version, some of the contributions were published in English and others in Spanish, as compiled within the book of proceedings (Díaz \& Salto, 2008). However, the papers collected here are reworked from the feedback gained within the arena of discussion and from the translation of the most Spanish papers contained in the mentioned book. For this second duty, the editors wish to acknowledge the very generous effort by the English editor board of BITrum: Basil Al Hadithi, Rosa Macarro and Mercedes Osorio, in the reviewing of the translations.
\end{abstract}

Twe his issue poses the question: what information really is. The reality or way of being of information is called into question. Consider for a moment we were to ask what digestion really is. Digestion might be considered as a complex collection of biochemical processes allowing for many distinct levels of analysis in reality: molecular, atomic, quantum... Let $d$ be a coherent complete description of such processes. Is digestion really $d$ ? It seems not, since our particular experience of digestion, our digesting, also seems to be part of what digestion "really" is. Moreover, we may ask whether digestion really occurs only within the organism, or rather there are external social phenomena determining what digestion "really" is. Regarding digestion there are also norms, values, indeed also ethical values, expectations and practices that are also part of what digestion "really" is. Reality is many sided and seems to include, from a manifest viewpoint, facts and also further nonfactual elements.

Even concerning digestion, this holistic viewpoint is far from obvious, and it is not our aim here to advocate for it or against it. There is however an important presupposition involved in asking what information really is: we assume that information has some place or other in reality, in particular, we assume there is a cohesive and coherent account of informational phenomena, able to coherently set up facts, contents and values regarding information. In our current information era it seems natural to assume without further critical reflection a disunited class of uses of "information". The point of this issue of tripleC is setting up a cohesive account of information in complex contemporary open societies and scientific communities.

There are at least three dimensions in our plea for such cohesive account of information: (a) from a conceptual point of view, there is a plethora of seemingly incompatible notions of "information", (b) from a societal viewpoint, information can acritically postulate a new infinite realm of merchandise which does not foster a more cohesive society but instead a growing inequality, (c) a coherent unified approach to both the manifest image and the scientific image of information is still lacking (Sellars, 1962).

However, no trace of this need for cohesion is left in the recurrent emphatic claims about the benefits and promises of the "information 
society", as for example in the Bangemann report to the European Council: "The information society has the potential to improve the quality of life of Europe's citizens, the efficiency of our social and economic organization and to reinforce cohesion" (Bangemann et al., 1994, §1). Since it is hard to conceive cohesion in the societal realm without a minimal agreement about what it is understood and expected regarding "information", these claims must presuppose some tacit accord, which can be hopelessly searched by collecting the notions of information given in the street or by mathematicians, physicists, biologists, sociologists, psychologists, engineers, librarian scientists, etc.

Furthermore, watching -in the economical realm during the advent of the so called "information society"- the actual evolution of the constantly growing inequality in the access to global resources among national and international populations (Atkinson, 2009; Milanovic, 2007), should we not question the promises of the "information society"? As a mirror of the societal interest, should we not strive for a cohesive account of information?

\section{Scientific agreement and the Meeting of Experts held in León (Spain, 2008)}

Let us now consider the most agreed concept of information among scientists, i.e. the shannonesque definition (Shannon, 1949) -although being generally considered by experts as partial or improvable in very different senses-, we find out that the same amount of information compiled in the whole librarian history may also be generated by a whim of electrons in a rheostat which random currents were observed by an extremely sensitive receiver for a couple of hours. Thus, the whole human writing effort is somehow put at the same level than the blindness of a rheostat. If this is the deepest cohesion that we are able to agree in the scientific understanding of our information society regarding its very core, something must be wrong.

However, if we pay attention to what the experts tell us about information: we would hear that there are information phenomena in cells, words, antennas, skin, cables, thoughts, electrons, brains, communities, robots, populations, institutions... And not just playing an ancillary role, but frequently -and in a growing proportion- a very central one. This centrality and the complexity of the regarded theories means that in order to obtain a good picture about what is understood about information, we should pay a very careful attention to each other's point of view. But if going much further than a neutral observation- we strive to overcome the forementioned lack of cohesion, we then would feel the need of sitting together all these points of view... That is what we tried by organizing the I International Meeting of Experts in Information Theory -An interdisciplinary approach- held in November 2008 in León (Spain). We were of course not the first in this attempt, and our effort consisted also in gathering the path started before us by the Foundations of Information Science (FIS), the project of the Unified Theory of Information (UTI), the chairs of Philosophy of Information, Information Ethics, Information and Library Science, and other scientific domains which have tried to achieve a common perspective about information. We tried to summon these pioneering efforts together with other scientific and technical domains in the endeavor of a more coherent understanding of Information phenomena.

But just, how should these perspectives be called for an effective summoning? If we take a careful look at the content of those theories where information plays a major duty, we often encounter precisely an antithetical observation: on the one hand, the central role given to information by each different discipline -very disconnected from othershas scattered its meanings and established important gaps among them (Capurro \& Hjørland, 2003); but on the other hand, an information theoretical approach may bridge apparently irreconcilable disciplines -as it has been oft envisaged (s. Schrödinger, 1944; Lyre, 2001; Conrad \& Schwarz, 1998; Marijuán, 1998; Hofkirchner, 1999). These extremes of cohesion -factual the first and promissory the last- were very illustratively recalled by Peter Fleissner in the Meeting of León as Babel vs Pentecost. 
As we did not expect the supposed grace of Pentecost, we had to circumvent the babelian dangers of the summoned perspectives. Thus, we had to find a stage in which the respective theoretical interests could be properly considered. For this purpose, the consensus around the shannonian sense of information was of course not enough. However, relying on the accord over some syntactical issues, gave us the path to find a solution to get a more comprehensive understanding: some theories address their selves to understand -beyond syntax- the semantic problems; while others concentrate at the pragmatic issues.

After a very illustrative and summarized exposition by Rafael Capurro* ${ }^{\star^{1}}$ about the "Past, present and future of the concept of information", we tried to arrange the stage where the major issues of semantics and pragmatics where considered in their specific domains of interest. Thus, we reserved the first round tables to argue about "the semantic question", and the second to do it about "the pragmatic question".

The enhancement of cohesion faces many difficulties, where the major discrepancies concern ontological and epistemological positions. For this reason, before arriving at the question of a cohesive point of view, we argued these thorny issues in a third round table: "Is information an objective or subjective category?" Finally, we entered in the last table to the core problem: "Is it possible a unified theory of information?"

In order to ensure a critical debate, in every round table, four speakers should face a set of critics, who had previously received the papers. After the exposition of the speakers, the critics had the voice, followed by the rest of the audience. Some papers were not presented by speakers, but were recalled within the debates.

\footnotetext{
${ }^{1}$ Author names followed by asterisk correspond to the works compiled within this issue. Any other contributions -from authors not marked by asterisks- are available in Spanish in Díaz \& Salto (2008), online accessible in: $<$ http://sites.google.com/site/ebitrum/archive>
}

\subsection{The semantic question (context, truth, contradiction)}

Images, words, thoughts, actions seem to be able to point to real or imaginary states of affairs, quite distinct and causally disconnected from them. Images, words, thoughts and actions show aboutness or the capacity to represent. Those abstract objects multiple realizable in distinct representations we may call contents or semantic contents. Explaining the nature of semanticity and aboutness is one of the main open trends in knowledge and also a main divide within uses of "information". Semantic uses or assumptions of information take for granted that information is real as content.

How does semanticity fits in nature? The traditional point of view -with strong arguments in its favour- locates content beyond nature, in the mind. Externist and nonmentalists points of view tend to naturalize content, beyond its seemingly abstract character. All contributions in this semantic table tackle from distinct perspectives the semantical nature of information.

Floridi* offers a new realist argument based on correctness for the veridical character of information when considered "strongly" semantical. Ostalé* puts forward a general set of conditions for informational semanticity based on common language analysis. The approach of Amat* is for the contrary "weakly" semantical, offering a constructivist approach based in conditional and reflected entropy and a fuzzy sense of meaning. Alvarez* distinguishes in his paper distinct senses of semanticity in biosemiotics and memetics, contrasting both strong and weak approaches.

Paradox and logical consequence is a main semantical concern in the philosophy of information. The contributions by Sagüillo*, Robles* and Vázquez* face distinct logical aspects of the semantic question of information, namely informational consequence, consistency concepts and monotonicity, respectively.

Concerning the influential situational understanding of semantic information, the paper of Aguilar, Sánchez and Campos* regards audiovisual content, while the one by Florio* addresses propositional content. 


\subsection{The pragmatic question (system, person, society)}

Regarding pragmatics of information, the argument was launched by a four edge confrontation in which the interests and problems at stake were argued: $1^{\text {st }}$ ) from a societal viewpoint with respect to economical, historical and legal issues by Peter Fleissner*; $2^{\text {nd }}$ ) from the perspective of individual as right holders by Juan Carlos Fernández-Molina*; $3^{\text {rd }}$ ) from the concern of organizations by $M$. Pérez-Montoro; $4^{\text {th }}$ ) from the role of political power in their social commitments by Félix Barrio. But the arguments, partially discussed in a somehow heated table, went much further in the texts, where: Christian Fuchs ${ }^{*}$ argued for the urgency of a "critical theory of information" in which a careful analysis of information and its technologies might allow us to strive for a fare and participatory society; Estela Mastromatteo* emphasized the preconditions for a sustainable human development, particularly referring to Latin America; J.M. Díaz \& B. Al Hadithi argued for the need to consider semantic aspects in the technological problem and to transcend its naive communication model; J.A. Moreiro et al.* posed the problem of artificial languages in information management; and, finally, Barrionuevo highlighted the antinomies of the scientific production in the information society.

\subsection{Is information an objective or subjective category?}

The round table on objective/subjective nature of information retakes the open issues left in the semantic table. It is opened with a conference by A. Galindo presenting qbits as uninstantiable fragile informational units, thus distinguished from bits and at the same time posing the indeterminacy of observation and the inseparability of object and subject of observation, which obviously affects to the very core of our question.

Papers by Liz* ("Information, world and mind") and Campos* ("Information: objective?, subjective?, redundant?") offer two competing conceptual approaches to content from a realist stance. Both are relevant philosophical contributions to the understanding of the nature of information.
Contributions by Ortiz ("Neural Communication: Approaching behaviour from brain rhythms") and Gutiérrez ("Information and informative functions in linguistics") use information in radically distinct senses, whose opposition is conceptually fruitful. Information in the brain is understood as a electrochemical signal, while natural language information is typically conceived as strongly semantical. However, both approaches call themselves functional.

Aguado's* paper ('Information, observation and self-reference") offers a constructivist viewpoint on information and communication based on a theoretical analysis of observation.

\subsection{Is it possible a unified theory of information? (Reductionism, holism, unified theory)}

At this table the controversy focused on the -so to say- senior discussion about the feasibility of a unified theory of information, gathering together the participants of such discussion held for some fifteen years: in the proponents side, Wolfgang Hofkirchner and Pedro Marijuán; in the side of critics, Rafael Capurro and Peter Fleissner. Thus a sceptic and an advocate position were represented at each side. While Hofkirchner* tried to settle the necessity and requirements for a unified stage, Marijuán* argued for a not unified "ecology of domains" as a "new panoramic view on the recombination processes of the sciences themselves" in order to effectively gain problem-solving ability. Such scepticism was also emphasised from a hermeneutical position by Capurro.

But the question for unification also included two other issues: 1 ) the possibility to bridge among information concepts in order to explain a major scientific problem, life (Juan Lara*), although the limits to gain here some cohesion -as argued- showed that in the bridging task a metaphorical use might be tolerate -at least in early stages- 2) a triadic approximation to information and its measure by A. Marcos, and a proposal by R. Gejman* for new definitions about information, communication and knowledge to settle a unified bench. 


\section{BITrum project}

By gathering together all these outstanding positions, we did not certainly pretend to find at the stage solutions to the posed questions, but rather to offer the possibility of distinguishing the courses we might follow to search for better answers and to foster a longtermed interdisciplinary approach in the elucidation of the information concepts. To this endeavour, an interdisciplinary group was founded with the general and agreed objective of "trying to define maximally general notions without neglecting particular interests or objectives sheltered by any point of view and, moreover, distinguishing different analytical levels: concepts, metaphors, theories, consequences and applications". The instituted group and its programme were named BITrum, recalling the outstanding stained-glass windows -vitrum- of Leon's Cathedral, in which vicinity the group was meeting. In analogy to how a multiplicity of colours, nuances and shapes -potentially joined in solar light- are summoned in these windows by expert and patient work, BITrum aims at gathering the multiple ways to see information. For more information about the project objectives, programme, ongoing activities, members, etc. can be visited its web site: <http://sites.google.com/site/ebitrum/>.

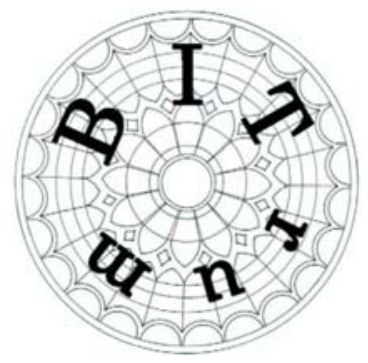

Figure 1: BITrum logo

\section{References}

Atkinson, A. B. (2009). Unequal growth, unequal recession? OECD Observer, 270/271. [Online] $<$ http://www.oecdobserver.org> [Accessed: 30/09/2009]

Bangemann, M. et al. (1994). Bangemann Report, Europe and the Global Information Society. To the European Council, June, 1993. [Online] <http://www. cyber-rights.org/documents/bangemann.htm> [Accessed: 30/09/2009]

Capurro, R, Hjørland, B. (2003). The concept of Information, Annual Review of Information Science and Technology, 37(8), 343-411

Conrad, M., Schwartz, A.W. (Eds.) (1998). Special issue: Foundations of Information Science. The quest for a Unified Theory of Information. Bio Systems, 46(1,2)

Diaz Nafría, J.M. \& Salto Alemany, F. (2008). ¿Qué es información? (What is information? Proceedings of the First International Meeting of experts in Information Theories. An Interdisciplinary approach). León (Spain): Universidad de León. [Online] <http://sites.google.com/site/ebitrum/archive> [Retrived: 24/10/2009]

Hofkirchner, W. (Ed.) (1999). The quest for a unified theory of information. Amsterdam: Gordon and Breach.

Lyre, H. (2001). Informationstheorie, Munich: W.Fink Verlag.

Marijuan, P. (Ed.) (1998). Special issue of Foundations of Information Science. Cybernetics \& Human Knowing, 5(4).

Milanovic, B. (2007). Worlds Apart: Measuring International and Global Inequality. New Jersey: Princeton University Press.

Sellars, P. (1962) "Philosophy and the scientific image of man" in R. Colodny (Ed.). Frontiers of Science and Philosophy, Pittsburgh: University of Pittsburgh Press, pp. 35-78.

Shannon, C. E. (1949), "Communication in the presence of noise". Proc. IRE, 37(1), pp. 10-21, Jan. 1949.

Schrödinger, E. (1944). What is life? The physical aspect of the living cell. Cambridge: Cambridge University Press.

\section{About the Authors}

José María Díaz Nafría

Obtained M.Sc. in telecommunication engineering from the Universidad del País Vasco, Bilbao, Spain, and received his $\mathrm{PhD}$ in telecommunication engineering from the Universidad Politécnica de Madrid with a dissertation on "Contributions to the electromagnetic inverse problem". He was also awarded with a M.A. in Philosophy by the Universidad Nacional de Educación a Distancia (UNED). He is currently visiting professor at the University of León and part of the board of directors of the Science of Information Institute, where he is also scientific advisor. He is members as well of several international scientific societies in the field of information theories. 
He was research fellow at the Vienna University of Technology and at the Technical University of Madrid. He also served as professor at the University Alfonso X el Sabio in Madrid between 1997 and 2009. He has been visiting lecturer at the University of Furtwangen, Sankt Pölten University of Applied Sciences and University of Salzburg. Co-director of the "First International Meeting of Experts in Information Theories" (León, Spain, 2008) and the "Colloquium BITae" (León, Spain, 2009) currently coordinates an interdisciplinary research group meted around the BITrum project (Elucidation of the information concept) and co-edits with F. Salto and M. Pérez-Montoro the forthcoming Glossary of concepts, metaphors, theories and problems concerning information (Universidad de León, 2010), where he authors several articles.

\section{Francisco Salto Alemany}

(Graduate in Philosophy and PhD, Universidad de Salamanca, Spain) is Professor of Logic at the Universidad de León (Spain) since 2002, Lecturer at the Institute for Logic, Cognition, Language and Information (University of Basque Country), co-founder and co-director of the research group BITrum for an Interdisciplinary Elucidation of the Information Concept; Fellow and co-founder of the Research Group in Philosophical Logic at the University of Salamanca; Member of the Humanities Group of the University of León, the Unified Theory of Information Research Group (Austria) and is Scientific Advisor of the Science of Information Institute (Washington). He was Assistant Professor at the Universidad de Salamanca, Visiting Fellow at Princeton University and Scholar at the Ruhruniversität Bochum.

His research work in mathematical logic embraces: Logic without Contradiction, Positive Non Classical Negation, Axiomatization, Identity, Games and Game Semantics (developing the software system Ithaca), which has been publicized in different international Journals devoted to Logic. He has also authored several works in philosophy, edited in Theoria, Analecta Husserleana, Phil. Zeitschrift, etc. Dr. Salto co-edits with J.M. Díaz and M. Pérez-Montoro the forthcoming Glossary of concepts, metaphors, theories and problems concerning information (Universidad de León, 2010), where he has authored several articles. 